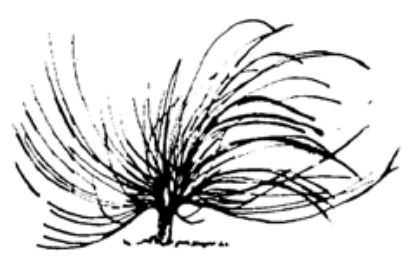

\title{
Fundamentos curriculares de un currículo crítico para el nivel preuniversitario en Costa Rica
}

\author{
César Toruño Arguedas1 \\ CONESUP \\ San José, Costa Rica \\ cesartoruno@gmail.com
}

\begin{abstract}
Resumen
El ensayo realiza una propuesta de fundamentos curriculares para un currículo crítico en Costa Rica a nivel preuniversitario, aunque las premisas expuestas son extrapolables a alternativas curriculares que difieran del sistema tradicional. A partir de un análisis de contenido de documentos teóricos en diferentes disciplinas, se plantean los fundamentos pedagógicos (pedagogía crítica), psicológicos (aportes de Vigotsky), sociológicos (sociología de la educación) e histórico contextuales (interpretación del contexto en que se desarrolla la propuesta educativa). La reflexión permite establecer la viabilidad, pertinencia y relevancia de estos fundamentos para la construcción de una alternativa curricular coherente con la pedagogía
\end{abstract}

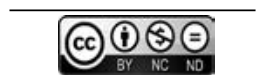

Recibido: 5 de abril de 2016-Aprobado: 22 de setiembre de 2016

1 Doctor en Ciencias de la Educación y Máster en Planificación Curricular. Asesor Nacional en Currículum, Consejo Nacional de Enseñanza Superior Universitaria Privada. Ministerio de Educación Pública, Costa Rica. Coordinador Proyecto Sortilegios Educativos. 
crítica, el currículo crítico y las demandas del progresismo pedagógico costarricense.

Palabras clave: Currículo, currículo crítico, pedagogía crítica, Costa Rica.

\begin{abstract}
This essay drafts a proposal for the curricular fundamentals for a critical curriculum in Costa Rica at pre-college level. Still, the premises posed are extrapolated from curricular alternatives might differ from the traditional system. Based on a content analysis of papers in different fields, the pedagogical (Critical Pedagogy), psychological (Vigotsky's contributions), sociological (Education and Sociology), and historical contextual (interpretation of the context where this education proposal is built) fundamentals are stated. The reflection allows for establishing the viability, pertinence y relevance of these fundamentals for the construction of a coherent curricular alternative for Critical Pedagogy, Critical Curriculum, and the demands of Costa Rican pedagogical progressivism.
\end{abstract}

Keywords: curriculum, Critical Curriculum, Critical Pedagogy, Pedagogical Progressivism, Costa Rica

\title{
1. Introducción
}

La construcción de una educación alternativa en Costa Rica exige una transformación de la reflexión y acción curricular, donde resulta relevante el debate de los pilares del diseño curricular del sistema educativo preuniversitario, a saber, los fundamentos curriculares, es decir, la "sustentación teórica dada por el contexto socio histórico del sistema educativo, que enmarcan el proceso de construcción curricular, principalmente, la creación de los perfiles de salida, selección cultural y su respectiva operacionalización" (Toruño, 2010, p. 8).

Por lo anterior, el presente ensayo expondrá una propuesta de reconceptualización de los fundamentos pedagógicos, psicológicos, sociológicos e histórico-contextuales para el currículo preuniversitario, 
estableciendo limitantes epistemológicas, conceptuales y metodológicas para la construcción de un diseño curricular alternativo coherente con tendencias educativas críticas, los movimientos pedagógicos progresistas en Costa Rica y pertinente en el contexto de nuestro país.

\section{Fundamento pedagógico: La pedagogía crítica}

La pedagogía crítica es un área de estudio pedagógico producto del legado de la Escuela de Fráncfort y la teoría crítica de la sociedad con sus respectivos aportes (Domínguez y Lugo, 2013), desarrollada a partir de la década de 1950 y de las investigaciones y reflexiones realizadas desde la escuela marxista anglosajona, principalmente inglesa. Esta establece características del sistema educativo explícitas e implícitas propuestas por Marx, por ejemplo, productora y producto de las relaciones sociales, la necesaria transformación de la sociedad (mediante una acción revolucionaria) como antecedente al cambio estructural en el sistema educativo, una educación para la clase obrera y anticapitalista, educación gratuita, entre otras (Soares, 2012)

En la década de 1960, Pierre Bourdieu identifica la educación, y el centro educativo, como construcciones culturales donde se genera un "capital cultural" (Bourdieu, 1997) que visibiliza una violencia simbólica en procura de la conservación de la estructura dominante (Bourdieu y Passeron, 2001); a partir de esta conceptualización, la pedagogía crítica reestructura sus estudios desde el enfoque de la educación como espacio cultural como respuesta ante las visiones tradicionales de la educación como escenario natural, neutral y objetivo que invisibilizaban los conflictos que se daban en el sistema educativo (Giroux y McLaren, 1998), por tanto, el movimiento reivindica que "las escuelas no son ideológicamente inocentes" (Giroux, 2006, p. 205).

La nueva interpretación (capital cultural y los centros educativos -sistema educativo) permite, a la pedagogía crítica, asumir estos espacios con posibilidades para la lucha contra la dominación, la liberación del sujeto y la transformación social revolucionaria, para lo cual resultaron clave los aportes de Freire, al establecer la educación como espacio político (Freire, 1990), práctica de libertad (Freire, 1977) y dirigida a la liberación del oprimido (Freire, 2005), un "tiempo subjetivo concreto, comunitario y crítico, se descubre la realidad social como algo que está comenzando a ser, como algo que se está haciendo" (Fernández, 2011, p. 4). 
A finales de los sesenta e inicios de los ochenta, la pedagogía crítica impulsó estudios que rechazaron la simplificación de la escuela como un sistema reproductor de las relaciones de poder y los intereses de los poderes dominantes (Giroux, 2006), reconociendo el sistema escolar como un escenario de confrontación entre intentos de implementación de proyectos ideológicos, socioeconómicos y culturales y, por otro lado, escenario de resistencias y producción de alternativas frente a la oficialidad y normalidad; es decir, hay relaciones pedagógicas que deben ser reconocidas como relaciones de poder y resistencias (Giroux; McLaren, 1998), para lo cual ha desarrollado alternativas metodológicas y de análisis (Cabello, 2003), con los cuales se develan el papel del Estado, los grupos de presión y la estructura política en la estructuración del sistema educativo (Giroux, 1997).

La pedagogía crítica incorpora conceptos nuevos para el análisis de la educación dentro de las estructuras sociales, como "la reproducción, el Estado, la legitimación, la acumulación, la contradicción, la hegemonía ideológica base/superestructura" (Apple, 1997a, p. 32); y una nueva visión de los sujetos educadores como intelectuales transformadores que "deben ser capaces de enfrentar cuestiones relacionadas con la función más amplia del currículum y de la escuela, así como manejar las relaciones entre cultura y poder" (Giroux y McLaren, 1998, p. 85).

Repensar los roles de los agentes educativos, las relaciones de poder, los contextos sociopolíticos y otros elementos invisibilizados constituyen aportes fundamentales de la pedagogía crítica a los análisis de la educación como institución social, ya que permite la construcción de análisis (y propuestas) integrales y pertinentes a las diversas realidades educativas sustentadas, implícitamente, por la premisa de Apple (1997b, p. 55 ) de que "hasta que no comprendamos los vínculos existentes entre las prácticas pedagógicas, los planes de estudio escolares y las estructuras 'externas' de dominación social, tendremos una explicación necesariamente incompleta".

Para el caso costarricense, esos vínculos se establecen a partir de las estructuras externas como el modelo económico (neoliberal o Interventor) y los grupos de presión asociados (cámaras empresariales, intelectuales orgánicos, inversores, partidos políticos, sindicatos, organizaciones comunales, empresas nacionales de tamaño medio o pequeño, entre otros). Estas estructuras generan planes de estudio (perfiles 
de salida, ciclos, ofertas educativas, división del tiempo pedagógico, asignaturas, entre otros), programas de estudio (enfoque, contenidos, actitudes, mediación y evaluación), visión ontológica, organización administrativa y sistema pedagógico concatenado con el modelo político-económico.

Tanto las estructuras externas como la estructura tácita del currículo (leyes, fundamentos, programas de estudio, organización administrativa pedagógica, etc.) pueden determinar la contextualización curricular; no obstante, esta última se condiciona, adicionalmente, por estructuras subjetivas y objetivas en una dinámica dialéctica que, en los términos de la pedagogía crítica, puede representar un espacio de resistencia contra el proyecto hegemónico que trata de ser implementado en el sistema educativo. Por lo tanto, desde una posición crítica y comprometida, correlacionada con la pedagogía crítica, la enseñanza no es "una técnica para conseguir metas en abstracto, porque esas metas no pueden ser cualquier fin y por los medios para conseguirlas operan en contextos inciertos, sobre seres humanos que imponen criterios a lo que se haga con ellos" (Gimeno, 1998, p. 53) y se realiza dentro de los rituales micro y macro llevados a cabo en nuestras aulas (McLaren, 1996; 1997; 1998).

Justamente, a partir de la comprensión de la enseñanza como acto cultural con trascendencia más allá de la acumulación-transmisión de conocimientos, se asumen los objetivos de los ciclos, las asignaturas y las unidades, como espacios políticamente diseñados, con una orientación cultural, económica y social y, por último, con un currículo oculto (Torres, 1998) de destrezas, actitudes y sensibilidades.

Los conocimientos son concebidos como una forma de capital cultural (Apple 1997a, 1997) y conocimiento oficial (Apple, 1996a) donde destaca del abordaje curricular de temas de etnias, clase y género; incluso Apple (1996b) indica que la política cultural de la educación no puede dejar de lado, además de lo indicado previamente, visiones acerca de la familia, la política cultural, diferencia e identidad y el papel del Estado. Esto debe ser complementado con el aporte de Giroux y McLaren (1998) en relación con la importancia del lenguaje en la construcción de la realidad y las subjetividades. Por su parte, las actividades de mediación son consideradas espacios para la construcción del diálogo, la democratización del proceso de enseñanza-aprendizaje y la 
creación de simbolismos enmarcados en la liberación, la resistencia y la esperanza.

La contextualización curricular, desde la pedagogía crítica, es analizada a partir de los materiales didácticos, principalmente desde los libros de texto por cuanto, como establece Apple (1996a, 1996b, 1997a y 1997b), estos materiales presentan un currículo operacional que conlleva intencionalidades que responden a grupos de interés externos así como, en determinados casos, un currículo oculto alejado de la política educativa oficial.

A nivel del perfil de ciudadanía y ser humano, a los que se aspiraría desde la pedagogía crítica, Gimeno (1998) establece valores que pueden ser aplicados desde la comprensividad o la pedagogía crítica:

En primer lugar, la atención a las necesidades individuales involucra la asimilación de cada estudiante como ser con sensibilidades y conocimientos, sujeto constructor activo de su aprendizaje, ser humano y ciudadano capaz de razonar, deliberar, argumentar y negociar.

En segundo lugar, la priorización de la integración comunitaria implica la comprensión del sistema educativo relacionado con la sociedad, la interacción centro educativo y su comunidad así como la integralidad del ser humano (tanto docente como estudiante) como producto y constructor de estructuras sociales y condicionantes que afectan los procesos de aprendizaje.

En tercer lugar, la inversión de recursos, por criterio de necesidad de estudiantes y centros educativos, permite la construcción de los principios de equidad y solidaridad como política de Estado en el área educativa. Asignar los recursos por necesidad permite ofrecer condiciones materiales (infraestructura, materiales, inmobiliario), humanos (personal docente, administrativo y equipo interdisciplinarios) y económico (subsidios y becas) para facilitar la integración de estos estudiantes, su movilidad social y la construcción de una legitimidad sociopolítica.

La cooperación entre escuelas y estudiantes es el cuarto factor y se convierte en un regulador conceptual y moral diferenciador del neoliberalismo, ya que desecha los principios de individualismo y competencia para dar paso y preponderancia a la colaboración, el trabajo en equipo, la solidaridad y la integración como ejes estructuradores de las relaciones y los procesos de aprendizaje.

Por último, la evaluación integral y valoración de la escuela, a partir del criterio de igualdad de condiciones, rompe con la visión 
industrial extrapolada a la educación ligando el proceso educativo con la elaboración de un producto que puede ser fabricado igual sin sus circunstancias personales o sociales y que pude ser evaluado, tanto en sus etapas como en producción final, con criterios seudoobjetivos y homogenizadores. Ante esta visión de evaluación tradicional, Santos $(1995 ; 1999 ; 2003 ; 2010)$ desarrolla la conceptualización de la escuela a partir de su papel como espacios democráticos condicionados por el género; el ejercicio autoritario del poder; la limitación a la participación de minorías; marginación de grupos por origen étnico o clase social; la disparidad en edades; el papel (y peso) asignado a docentes, estudiantes y otros grupos participantes del centro escolar; la poca participación (real y efectiva) de representantes y sujetos representados, de padres y madres, y estudiantes; y las debilidades de los canales de información para asegurar una participación plena con información veraz y rápidamente divulgada.

Por tanto, la pedagogía crítica permite constituir una nueva propuesta curricular por cuanto "está sobre todo interesada en examinar cómo la estructura educativa y el currículo interactúan y dan forma al conocimiento" (Magendzo, 2003, p. 22).

\section{Fundamento psicológico: Vigotsky y la incorporación de lo social en el debate epistemológico y pedagógico}

Al iniciar el siglo XX, Lev Vigotsky realizó una ruptura psicológica, epistemológica y pedagógica con la presentación de una serie de planteamientos y teorías sustentadas en el principio de que el pensamiento, aprendizaje y las funciones "psíquicas superiores" son un producto cultural, específicamente, diversas funciones cognitivas-neurológicas son producto de la interacción del individuo con la sociedad, priorizando la construcción y empoderamiento del lenguaje. El mismo Vigotsky (2001, tomo II, p. 15) señala esta ruptura al indicar que el análisis atomista y funcional "dio lugar a considerare las funciones psíquicas de forma aislada y a elaborar y perfeccionar métodos de investigación psicológica aplicados al estudio de esos procesos aislados y separados entre sí”, posiciones que serían superadas en los trabajos del autor.

Para Vigotsky, según Chaves (2001, p. 62), "lo que determina el desarrollo ontogenético del ser humano tiene la siguiente estructura: 
actividad colectiva y comunicación- cultura (signos)-apropiación de la cultura (enseñanza y educación)-actividad individual-desarrollo psíquico del individuo", es decir, un proceso de interacción dialéctico (individuo-contexto) que permite la reconstrucción externa e interna del primero y posibles alteraciones del segundo. Vigotsky (2001, tomo II, p. 59) sintetizaba esta concepción al afirmar que la "verdadera dirección del proceso de desarrollo del pensamiento del niño no va de lo individual a lo socializado, sino de lo social a lo individual".

La ruptura de Vigotsky y los aportes de sus investigaciones deben ser comprendidos en el marco de la influencia marxista; como afirman Barba, Cuenca y Rosa (2007, p. 5), revolucionó toda la teoría psicológica "desde las posiciones de la dialéctica materialista, hecho que le permitió aseverar que el desarrollo ocurre como resultado de la asimilación de la experiencia histórico-social y se produce gracias a la actividad y comunicación del niño con el medio social". La introducción de marcos conceptuales marxistas queda plasmada al afirmar que:

Todas las funciones psíquicas superiores son relaciones interiorizadas de orden social, son el fundamento de la estructura social de la personalidad. Su composición, estructura genética y modo de acción, en una palabra, toda su naturaleza es social; incluso al convertirse en procesos psíquicos sigue siendo cuasi-social... Modificando la conocida tesis de Marx, podríamos decir que la naturaleza psíquica del hombre viene a ser un conjunto de relaciones sociales trasladadas al interior y convertidas en funciones de la personalidad y en formas de su estructura. (Vigotsky, 2001, tomo III, p. 151)

Establecer dicha relación, y sus implicaciones en los procesos de aprendizaje, significó una revolución en la psicología, epistemología y marco pedagógico en el siglo XX e implica, para el contexto costarricense al iniciar el siglo XXI, la posibilidad de interpretaciones, análisis y acciones pedagógicas coherentes con posiciones de la pedagogía crítica y el progresismo político, económico y cultural. Asimismo, sus postulados no pueden ser interpretados como deterministas "pues trasciende al biologismo, y se atreve a afirmar que lo que diferencia al cerebro humano del cerebro animal es la capacidad que tiene para organizar sus funciones superiores a partir de la interacción social" (Pineda, 
2011, p. 224), y establece que "la peculiaridad fundamental del desarrollo infantil radica en el entrelazamiento de los procesos de desarrollo: el cultural y el biológico" (Vigotsky, 2001, tomo III, p. 41), por tanto, el análisis y las acciones educativas vinculadas a estos postulados siempre deberán responder al contexto específico, dotándolas de especificidad temporal y espacial que impide su implementación, en forma exacta, en otro contexto o tiempo.

Para Vigotsky, los procesos de conocimiento "se originan en la interacción social y son exclusivamente humanos. Ellos regulan la acción en función del control voluntario y durante su organización usan formas de mediación, particularmente la semiótica" (Pineda, 2011, p. 226), en el marco de los sistemas culturales semióticos, entendidos como "la superestructura simbólica que, juntamente con la dimensión histórico-económica, da cierta forma y organización a la actividad de los individuos" (Radford, 2004, p. 10). En este marco conceptual, Vigotsky (2001, tomo III, p. 150) concluye que:

Podemos formular la ley genética general del desarrollo cultural del siguiente modo: toda función en el desarrollo cultural del niño aparece en escena dos veces, en dos planos; primero en el plano social y después en el plano psicológico, al principio entre los hombres como categoría interpsíquica y luego en el interior del niño como categoría intrapsíquica.

Además, Vigotsky (2001, tomo III, p. 313) establece como principio generador de su teoría el hecho de que:

El desarrollo de las funciones psíquicas superiores del niño sólo es posible por el camino de su desarrollo cultural, tanto si se trata de dominar los medios externos de la cultura tales como el lenguaje, la escritura, la aritmética, como por el perfeccionamiento interno de las propias funciones psíquicas, es decir, la formación de la atención voluntaria, la memoria lógica, el pensamiento abstracto, al formación de conceptos, el libre albedrío, etc... el desarrollo cultural es la esfera más importante donde es posible compensar la insuficiencia. Allí donde el desarrollo orgánico resulta imposible, hay infinitas posibilidades para el desarrollo cultural. 
Lo anterior se complementa con la introducción del término edad cultural, el cual obliga al investigador a que "no sólo nos debemos preguntar cuál es la edad real de cada niño, cuál es su edad intelectual, sino también en qué nivel de desarrollo cultural se halla" (Vigotsky, 2001, tomo III, p. 315). Esta concepción implica una vinculación directa del análisis pedagógico con elementos sociales, económicos, culturales y sociales, permitiendo la inclusión de elementos como proyectos hegemónicos, desigualdades sociales y económicas, capital cultural, resistencias y otras unidades de análisis propuestas desde otras áreas disciplinares y reivindicadas desde la pedagogía crítica.

Paralelamente, Vigotsky (2001, tomo IV, p. 189) introduce un principio que será compartido por la pedagogía crítica, según el cual "no todo contenido puede incluirse en cualquier forma. El contenido no es indiferente ante la forma del pensamiento, no la colma de modo puramente externo mecánico como llena el líquido recipiente", reestructurado por Freire (2005) como sistema bancario, o los estudios de Apple (1996a, 1997b) sobre las implicaciones de los contenidos en los libros de textos y como parte del proyecto hegemónico, así como McLaren (1995) sobre los contenidos en una contenida global. El contenido facilita la construcción de conocimientos para la libertad (Freire, 2001), por cuanto:

Sólo el concepto eleva el conocimiento de la realidad, le hace pasar del nivel de vivencia al nivel de entendimiento de la realidad, le hace pasar del nivel de vivencia al nivel de entendimiento de las leyes. Y sólo esa comprensión de la necesidad, es decir, las leyes, subyace en el libre albedrío. Vigotsky (2001, tomo IV, p. 200)

Todo lo anterior permite afirmar que los postulados del socioconstructivismo son coherentes y referentes para una propuesta de transformación del currículo costarricense, pues establece cambios epistemológicos sobre la comprensión de la construcción del aprendizaje (en relación dialéctica con el contexto) y las posibilidades para la reflexión-acción del currículo como producto cultural en interacción con un contexto cultural (política, economía, sociedad, arte, etc.) con grupos de presión, currículo oculto e intereses tácitos de un proyecto hegemónico.

La introducción de la cultura como elemento determinante en el desarrollo cognitivo, los procesos de aprendizajes y la socialización 
enmarcada en los sistemas educativos formales implica, como principios operacionales, la inclusión de áreas disciplinares como la sociología, antropología, lingüística, economía y política en los estudios educativos, donde resultan de especial importancia los aportes de la denominada sociología educativa o sociología de la educación, por cuanto permiten establecer las características del contexto, reinterpretar las características y posibilidades de la educación como sistema formal y expanden las interpretaciones-posibilidades de los análisis de la persona, tradicionalmente vinculados con la psicología.

A nivel regulatorio, la inclusión del socio constructivismo exige una transformación curricular para la reconstrucción del perfil de entrada y salida de estudiantes por ciclo, la inclusión explícita del socio constructivismo como parte de los fundamentos psicológicos-filosóficos, los procesos de selección y organización de contenidos (comisión de reforma de cada plan de estudio, integrantes, metodologías e insumos), una reestructuración de la malla curricular de las ofertas educativas para establecer las vinculaciones culturales y, finalmente, una transformación del rol docente.

Con respeto al papel del personal docente, no puede omitirse el hecho de que, en la realidad de la contextualización curricular, ha sido reducido a una labor técnica de reproducción de contenidos (propia del conductismo) con ligeros matices de constructivismo; no obstante, en el socio constructivismo los cuerpos docentes son responsables de "diseñar estrategias interactivas que promuevan zonas de desarrollo próximo, para ello deben tomar en cuenta el nivel de conocimiento de las y los [sic] estudiante, la cultura y partir de los significados que ellos poseen en relación con lo que van a aprender" (Chaves, 2011, p. 63), sin obviar la demanda desde la pedagogía crítica para convertirles en intelectuales transformadores y transformadoras (Giroux y McLaren, 1998).

\section{Fundamento sociológico: Sociología de la educación}

El reconocimiento del aprendizaje como producto sociocultural (Vigotsky y socioconstructivismo) así como la reivindicación de la educación como hecho cultural en el marco de interacciones de poder-resistencia de proyectos hegemónicos (pedagogía crítica) se enriquece a partir de los aportes teóricos de la sociología y la subárea de la 
sociología de la educación, en tanto introduce el reconocimiento de la importancia del contexto para la interpretación del sistema educativo, es pionero el estudio de Durkheim $(1975,46)$, al establecer que:

Si la educación romana hubiese llevado el sello de un individualismo comparable al nuestro, Roma no hubiese podido mantenerse; la civilización latina no hubiese podido gestarse ni, más adelante, tampoco nuestra civilización moderna, que procede en gran parte de ella... ¿de qué puede servirnos el imaginar una educación que resultaría funesta para la sociedad que la pusiese en práctica?

Con esta afirmación, Durkheim establece una ruptura con las interpretaciones dominantes de la época en las que, consciente o inconscientemente, se asumía la posibilidad de comparar sistemas educativos de diferentes espacios temporales y geográficos; con esta premisa, el autor restablece la importancia del contexto, al punto de afirmar que, si se preguntase por la educación ideal "haciendo caso omiso de toda condición de tiempo y lugar, es que, implícitamente, se admite que un sistema educacional no tiene nada de real por sí mismo" (Durkheim, 1975, p. 46).

En síntesis, Durkeheim conceptualiza la educación a partir de que tiene "por objeto el suscitar y desarrollar en el niño un cierto número de estados físicos, intelectuales y morales que exigen de él tanto la sociedad político en su conjunto como el medio ambiente específico al que ésta especialmente destinado" (Durkheim, 1975, p. 53), conceptualización que será ampliada (relación con la sociedad y postura crítica) durante el siglo XX y los estudios de la sociología educativa marxista posteriores a la década de 1960. Paralelamente a esta premisa, Durkheim (1945, p. 96) establece que la educación es "ente eminentemente social, tanto por sus orígenes como por sus funciones, y que, por ende, la pedagogía depende la sociología más estrechamente que de cualquier otra ciencia", con lo cual promueve la ruptura del dominio de la psicología en la interpretación y reflexiones pedagógicas, punto referencial para la renovación pedagógica desde interpretaciones críticas, en tanto, como afirma Masjuan (2003, p. 69), "las sociologías de la educación transformadoras analizan las escuelas que reproducen las desigualdades 
sociales e incluso las aumentan y las escuelas y actuaciones educativas que contribuyen a superarlas".

Además, la sociología permitió la integración del sistema educativo en la burocracia, entendía esta como:

Tareas y cometidos regulados de manera oficial, sujetas a una división funcional de trabajo, ordenada según una jerarquía de oficinas, regulada mediante normas de procedimiento y ocupada por funcionarios expertos y pagados que habrían ganado su puesto en virtud de los méritos contraídos. El aparato en cuestión estaría regido por normas impersonales y de una racionalidad calculada, de modo que los funcionarios desempeñaran sus competidos con independencia de las personas. (Weber, 1968, p, 975, citado por Tyler, 1996, p. 48)

Junto a los aportes de Durkheim, Weber y la reivindicación del papel de la sociología como disciplina fundamental para el análisis y transformación del sistema educativo, Louis Althusser (1989, p. 193) establece que "el aparato ideológico del estado que ha quedado en posición dominante en las formaciones capitalistas maduras-después de violenta lucha de clase, política, ideológica, contra el antiguo aparato ideológico dominante- es el aparato ideológico escolar", comprendidos los aparatos ideológicos del Estado con una función ideológica...

pero secundariamente de modo represivo, aunque sea sólo en casos extremos y suave, disimuladamente e incluso simbólicamente. (No existe un aparato puramente ideológico). Las iglesias y las escuelas "educan" con métodos apropiados y con sanciones, exclusiones, selecciones, etc. También la familia y también el aparato ideológico del estado cultural (la censura, por ejemplo, para no mencionar otra cosa). Althusser (1989, p. 94)

El concepto de aparato ideológico del Estado sitúa la educación como un sistema integrante de un proyecto hegemónico con la función social de forjar la legitimidad que permita la paulina disminución, o al menos la necesidad, de los aparatos represores. Esto adquiere relevancia en el contexto costarricense, por cuanto, desde la fundación de la Segunda República y la abolición del ejército, el Estado y los grupos 
hegemónicos asignaron una importancia estratégica al sistema educativo para la consolidación del modelo político, económico, cultural y social; incluso Althusser (1989, p. 191) afirma que: "ninguna clase puede detentar durablemente el poder del estado sin ejercer al mismo tiempo su hegemonía sobre y en los aparatos ideológicos del estado".

Althusser (1989, p. 94) sintetiza correctamente la importancia del sistema educativo al afirmar que este:

Recibe a los niños de todas las clases sociales desde los jardines infantiles y desde ese momento - tanto con nuevos como en viejos métodos- les inculca durante muchos años -los años en que el niño es más 'vulnerable' y está aprisionando entre el aparato ideológico familiar y el escolar- 'saberes prácticos' tomados de la ideología dominante (el idioma materno, el cálculo, la historia, las ciencias, la literatura) o simplemente ideología dominante en estado puro (moral, educación cívica, filosofía).

Los centros escolares y el sistema educativo en general, como aparatos ideológicos del Estado "pueden no sólo ser la piedra de toque, sino también el lugar de la lucha de clases y, a menudo, de formas encarnizadas de lucha de clases" (Althusser, 1989, p. 191), lo que introduce una variable dinámica para los estudios pedagógicos al tiempo que refuerza la superación de la concepción lineal y reproduccionista a la que había sido reducida la educación desde interpretaciones conservadoras, tanto de derecha como de izquierda. Es posible el análisis desde tres niveles: "estructural (formalización de reglas y procedimientos, jerarquía, especialización), comportamental (objetividad, formalismo, precisión e impersonalidad) y funcional (formas de adjudicación de plazas, remuneración y promoción de funcionarios)" (Tyler, 1996, p. 48).

En este contexto, resulta necesaria la explicitación de la premisa de que los centros educativos "existen en cuanto a organizaciones, no porque estén integradas en sentido estructural, sino porque encarnan determinados mitos legitimadores que se expresan en forma ceremonial y ritualizada" (Tyler, 1996, p. 85), elemento esencial para la formación de los Estados Nacionales, la consolidación de los proyectos hegemónicos y la reconfiguración de los Estados Nacionales dentro del proceso de globalización. 
Con respecto a la labor docente, se le conceptualiza como una labor cotidiana que se explica "como instrumento de transmisión cultural más compleja y no sólo se modela con los criterios puramente didácticos, sino que tiene sus orígenes en la dinámica social" (Fernández, 2003, p. 20), es decir, el personal docente es más que un grupo técnico aplicador de actividades didácticas para convertirse en un ente técnico reproductor o intelectual transformador, en el marco de una estructura social, proyecto hegemónico y finalidades educativas.

El conocimiento escolar es una categoría de análisis que ha adquirido relevancia en estudios posteriores a la década de 1970, en la cual, siguiendo a Fernández (2003), la sociología permite entenderlo como producto cultural que busca la dominación o liberación del individuo, la institución escolar como institución para la reproducción y legitimación social capitalista, con procesos de selección injustos en el tanto responden a procesos ocultos, el alumnado es un ser social en un determinado contexto, el aprendizaje escolar como las experiencias totales que vive el estudiantado y un sistema dirigido a la inculcación ideológica y domesticación en el marco de relaciones de poder y dominación.

A nivel regulatorio, las funciones del sistema educativo se conciben, según Granados (2003), como guardia y custodia de las generaciones más jóvenes, cohesión social y de construcción de identidades nacionales y formación para el trabajo y distribución de las posiciones sociales. Al respecto, Tyler (1996, p 38) establece que la función de "mantenimiento cultural (es decir, la interiorización de compromisos y capacidades) es fundamental para la comprensión del lugar que la escuela ocupa en el sistema social".

Lo anterior permite develar la importancia de la sociología de la educación no solo como generadora de marcos conceptuales para el análisis e interpretación de las realidades educativas sino, además, como área disciplinar que aporta técnicas y metodologías enriquecedoras para los procesos de investigación en el área educativa.

\section{Fundamento histórico: Evolución del currículo en perspecti- va contextual}

La educación, manifestada en el sistema educativo como institución cultural, es una construcción histórica y contextualmente estructurada, motivo por el cual su desarrollo práctico se encuentra en una 
relación dialéctica con proyectos hegemónicos en áreas políticas, culturales y económicas, y las resistencias y contraproyectos provenientes de los grupos dominados y excluidos, es decir, es un escenario de construcción cotidiana donde confluyen los más diversos, y muchas veces antagónicos, grupos de presión para asegurarse espacios de incidencia en el proyecto cultural.

El sistema educativo costarricense puede ser estudiado, históricamente, desde la división propuesta por Molina (2007), a saber: municipal-eclesiástico (1821-1885), el centralizado-secular (1886-1939) y el universitario-pedagógico (1940 en adelante). Este último periodo puede ser dividido en tres momentos no asumidos por el señor Molina.

Un primer momento ligado al proceso reformista (década de 1940) que logró la expansión de la proporción de niños y niñas de entre 7 y 12 años que asistía a la escuela, la cual pasó de $66,1 \%$ en 1938 a un $85,9 \%$ en 1950 (Molina, 2007, p. 259) y la inclusión de niños y niñas con discapacidad, mediante la escuela fundada por Fernando Centeno Güell.

Un segundo momento, que podemos denominar como el modelo pedagógico socialdemócrata (MPS), el cual estuvo ligado al proyecto económico intervencionista impulsado por el Partido Liberación Nacional y el cual puede caracterizarse como:

El modelo educativo implementado en Costa Rica posterior a la guerra civil (1948), ligado políticamente al Partido Liberación Nacional, sustentado en los preceptos de la Constitución (1949) y la división por ciclos y Fines de la Educación establecidos en la Ley Fundamental de Educación (1957), que asume la educación como instrumento de movilización social y distribución de la riqueza, con una función de educación integral (acercamiento a la cultura universal y desarrollo de una persona emocional y socialmente plena, según se puede inferir de los Fines de la Educación) y ligado al nuevo modelo económico mediante la formación de mano de obra especializada (colegios vocacionales, colegios técnicos, inclusión de asignaturas como Mecanografía en el currículo de colegios académicos y el Instituto Nacional de Aprendizaje). 
El MPS se operacionalizó mediante el aumento de la inversión en educación, la conceptualización del dinero dedicado a educación como inversión, la ampliación de la cobertura en secundaria (objetivo de inclusión social, movilización y construcción de legitimidad del proyecto político-económico), una nueva organización del Ministerio de Educación Pública (extrapolación empresarial del enfoque curricular técnico, correspondiente con la visión fragmentada y dirigida a maximizar el control-evaluación del producto educativo), el aumento de la estructuración de los procesos educativos (programas de estudio, materiales didácticos y otros), la fragmentación del conocimiento por asignaturas, programas de equidad (para la inclusión y permanencia de estudiantes de estratos económicos medio-bajo y bajo) y la ampliación de la oferta académica según necesidades del nuevo modelo económico. Toruño (2015b, pp. 13-14)

El modelo pedagógico socialdemócrata sufre las consecuencias de la crisis de 1978-1982 y el debilitamiento del Estado interventor-empresario, lo cual se traduce en el tercer momento de la educación costarricense posterior a 1940, el ajuste pedagógico neoliberal, el cual está intrínsecamente relacionado con la implementación del neoliberalismo como modelo político y económico, cuyos orígenes conceptuales se remontan a la década de 1970 en la escuela de Chicago liderada por Milton Friedman.

Siguiendo a Villarreal (1986), podemos caracterizar las implicaciones políticas del neoliberalismo, o monetarismo friedmaniano (en términos del autor), en primer lugar por cuanto los precios y salarios son perfectamente flexibles por lo que "el Estado no debe establecer ningún tipo de regulación de mercado ni de control de precios" (Villarreal, 1986, p. 97), a diferencia de Keynes y los neokeysianos, que consideraban el desempleo y la concentración del ingreso como los principales problemas del capitalismo, para la escuela de Chicago el problema residía en la inflación próvida por el exceso de dinero producto del intervencionismo estatal.

Se parte del supuesto de que el Estado es ineficiente, por lo que se deben recortar sus gastos; lo cual se complementa con la visión de limitar los impuestos, pues el sector privado puede redirigir esos dineros a áreas más rentables para la sociedad. Todo esto asume que "el Estado 
debe ser un Estado 'guardián' o 'policía' que vigile que operen 'libremente' las leyes del mercado (Villarreal, 1986, p. 99).

Esta teoría tienen un mayor impacto en la Costa Rica posterior a la crisis económica de 1978, para lo cual Vargas (2002) establece cuatro lineamientos identificables en su aplicación, principalmente en relación con los programas de ajuste estructural. Estos son: a) desregulación, b) reducción del tamaño del Estado, c) apertura de la economía costarricense a los flujos internacionales de comercio y capitales y, d) redescubrimiento del mercado externo como motor para el desarrollo económico a largo plazo.

Dentro de este proceso de reforma económica y política, paulatinamente los neoliberales trasladarán su proyecto a las esferas socioculturales de la sociedad costarricense, para lo cual implementan el ajuste pedagógico neoliberal que replanteó los marcos conceptuales con la reconceptualización de la "Educación", sustentado en la premisa de la educación como una mercancía que, en términos de Torres Santomé (2007), se visibiliza en los procesos de descentralización (delegación de poderes y funciones, desregulación, deszonificación y colegialidad competitiva), privatización, favorecimiento de credencialismo y de la excelencia competitiva y, por último, la naturalización de lo individual recurriendo al innatismo; lo cual se traduce en una transformación de las funciones del sistema educativo para centrarlo en un adaptador social del ser humano, reproductor de las relaciones de poder social y económico, homogenizante cultural, preparador para inserción laboral de cada ciudadano o ciudadana, entre otros.

Es imperativo comprender el ajuste pedagógico neoliberal como una consecuencia de lo que Miranda (2007) denomina crisis de legitimación ya que, expone el autor, la crisis de racionalidad administrativa del capitalismo regulado (1978) se traduce en crisis de legitimación; esto genera que la crisis se traslade al sistema sociocultural, en donde el sistema educativo toma un papel determinante ya que se revalora desde: a) modificación de los determinantes del proceso de valorización de capital y, b) proceso de legitimación del proyecto hegemónico de la nueva derecha. Como afirma Miranda (2001), el desplazamiento del sistema educativo durante la crisis estructural, del modelo socialdemócrata al neoliberal, ha tenido, como centro, "las funciones económicas de la educación en la reproducción de la fuerza de trabajo (selección y asignación de la fuerza de trabajo activa y del ejército de reserva) y en 
la inculcación de una disciplina acorde con la economía de mercado" (p. 30). Dicho desplazamiento, sumado a los valores éticos y socioculturales impulsados por el proyecto hegemónico neoliberal, se pueden apreciar en la transformación del proyecto de ciudadanía y los fundamentos curriculares que la sustentan (Toruño, 2010, 2011).

Resulta pertinente denominar a este período como un ajuste pedagógico neoliberal, en tanto no implicó, como en otros países latinoamericanos, la desintegración del modelo interventor en educación (en el caso de Costa Rica ligado con la socialdemocracia); por el contrario (Toruño, 2015b), durante la última década se ha consolidado el modelo pedagógico socialdemócrata, sin embargo, el ajuste pedagógico neoliberal incluyó elementos reguladores como inversión vrs gasto, intento de formación de consumidores y la transformación de la concepción del "ser humano y la ciudadanía" en relación con sus roles como agente productivo (en las áreas laborales y de consumo) en una sociedad de mercado.

En el marco de esta reconfiguración, se da un cambio en el "concepto de docente" para asignársele un rol técnico en la aplicación de estrategias didácticas para aumentar la productividad en la adquisición y uso de los conocimientos asumidos como válidos por los programas de estudio, dentro de una lógica capitalista y postfordista (Robertson, 1994); sus funciones se centran en supervisar los procesos de aprendizaje, repremir conductas no deseadas ni asumidas como legítimas, intermediar entre los conocimientos oficialmente reconocidos y lo aprendido por el estudiantado. Por su parte, el "proceso educativo" se visualiza como un sistema fabril en donde se darán una serie de acciones para convertir la materia prima (estudiante) en un producto (ciudadano y ciudadana-ser humano-obrero y obrera) que cumpla con las expectativas prediseñadas por el sistema educativo y el sector dominante.

Todo lo anterior implicó un replanteamiento de los principios operacionales, iniciando con el análisis del presupuesto en educación como gasto, costo por estudiante que se gradúa, aumento de eficiencia y efectividad, redirección a áreas estratégicas. Se continúa con una diversidad en la oferta académica, con un impulso estratégico a los colegios técnicos o vocacionales y la creación de los colegios científicos y los colegios experimentales bilingües, así como una desregulación a la creación de centros educativos privados

Paralelamente, se da una verificación de la transformación de la materia prima en el producto deseado mediante la restauración de las 
pruebas nacionales de bachillerato y la inclusión de las pruebas nacionales de sexto grado y noveno año. Además, la estructura administrativa y pedagógica se especializa con la profundización del modelo de departamentos académicos en cada institución, una marcada división entre las áreas técnicas y académicas dentro de una misma institución. A esto se suman las nuevas funciones y atribuciones de las gerencias educativas con nuevos perfiles de funciones y potestades de mandos medios, direcciones regionales, direcciones de instituciones, coordinaciones académicas y técnicas, comités de evaluación, coordinación de departamentos y docentes.

En este período se desarrollan nuevos métodos de control directo con la incursión de la boleta (reporte escrito de una falta cuya sanción en la nota de conducta se traduciría en una rebaja en los puntos finales) a inicios de la primera década del siglo XXI y la reconceptualización de la nota de conducta, ya no como una sanción moral-social sino como una nota académica que tendría impacto en las posibilidades de aprobar o reprobar un curso lectivo. Este proceso responde a lo que Apple (1996a, 1996b) ha denominado el ascenso del conservadurismo, el cual tiene una agenda de control simbólico, así como la instauración de una formación ciudadana de conocimientos fragmentaria, acrítica, sin contenidos problematizadores ni espacios para la autodeterminación; todos elementos rescatados desde la pedagogía crítica.

A partir del año 2006, y hasta la actualidad, se desarrolla el ajuste pedagógico progresista, el cual encuentra sus raíces en las preocupaciones expresadas por Leonardo Garnier Rímolo en el periódico la Nación entre el año 2002 y 2006 y las reformas implementadas entre el 20062014; además, estos principios fueron introducidos en el V Congreso Ideológico del Partido Liberación Nacional (Toruño, 2015).

Las reformas realizan una ruptura con el ajuste pedagógico neoliberal, al tiempo que muestran premisas, conceptos, habilidades y destrezas indicadas por la agenda progresista. En el área académica se presenta un revitalización de la formación ciudadana desde la integralidad, en evaluación se realiza una ruptura del sistema tradicional y en los programas de estudio se operacionalizan los principios constructivistas de la política educativa hacia el siglo XXI, todo esto continuado durante la presente administración de la actual ministra Sonia Marta Mora Escalante. Por tanto, se puede concluir que el escenario para la implementación de un proyecto educativo alternativo proveniente 
desde la pedagogía crítica u otro postulado del progresismo pedagógico no requiere un escenario de ruptura con el sistema educativo actual, sino un proceso de profundización posible desde la reflexión crítica del currículo.

\section{Conclusiones}

El sistema educativo costarricense se encuentra en un contexto nacional de ascenso de movimientos progresistas (tanto en la organización comunal-nacional como en las organizaciones políticas) y con la implementación de un ajuste pedagógico progresista que permite construir escenarios curriculares alternativos o críticos en escala local (centro educativo), regional (direcciones regionales) o nacional. En este contexto, es posible la construcción de diseños curriculares alternativos y críticos que consoliden las rupturas con el sistema tradicional y favorezcan las condiciones para la implementación de una contextualización curricular integral, crítica, pertinente y relevante.

Lo expuesto en el presente ensayo permite concluir que es posible la construcción del diseño curricular crítico a partir de los fundamentos de la pedagogía crítica (fundamento pedagógico), los insumos de Vigotsky (fundamento psicológico), la sociología de la educación (fundamento sociológico) y la interrelación dialéctica sistema educativo y el contexto socioeconómico, político y cultural (fundamento histórico). Específicamente, al asumir los siguientes fundamentos para el diseño curricular:

1. La educación y el sistema escolar son instituciones culturales que exigen un estudio sociológico para determinar su papel como aparato ideológico del Estado (1989), transmisor-reproductor cultural (Fernández, 2003) y funciones para el mantenimiento o transformación cultural (Tyler, 1996). Esto implica que los diseños curriculares en Costa Rica deben construirse desde la conciencia de estas premisas y la necesidad de asumir una posición (mantenimiento o transformación) frente al proyecto hegemónico.

2. El sistema educativo costarricense debe ser comprendido desde una nueva visión histórica que permita visibilizar, analizar y evaluar las características durante el modelo pedagógico socialdemócrata, el ajuste pedagógico neoliberal y el ajuste pedagógico 
progresista. La nueva perspectiva de análisis histórico de nuestro sistema implica que la construcción del currículo se realice desde posiciones complejas para la comprensión de la interacción de elementos disimiles; pero propios de la estructura pedagógica elaborada en el contexto nacional.

3. El sistema escolar como institución cultural responde a proyectos hegemónicos por lo que no son espacios neutrales, objetivos e inocentes (Apple, 1996; Giroux, 2006; Giroux y McLaren, 1998). Ante esta premisa, el diseño curricular costarricense debe realizarse desde la conciencia del rol de poder del currículo y de curriculistas, los intereses manifiestos y latentes, las presiones internas y externas y los agentes mediadores (docentes, editoriales y otros) y su influencia determinante en la contextualización curricular.

4. El currículo debe tener un compromiso con la liberación del ser humano (Freire) y una serie de principios éticos, ontológicos y metodológicos directamente vinculados a nueva sociedad. Por tanto, el currículo debe contemplarse como una plataforma pedagógica que permite (o no) el desarrollo de determinadas actitudes, sensibilidades, conocimientos, habilidades y destrezas; así como una herramienta cultural para la lucha de cambios en las realidades del contexto costarricense.

5. El contenido del currículo es un capital cultural (Bourdieu, 1997; Apple 1997a, 1997b); por tanto, objeto acumulable y reproducible en el marco de estructuras, visibles e invisibles, que determinan la distribución de ese capital y el mantenimiento o expansión de brechas de desigualdad académica. Esto exige comprender los programas más allá de un listado de contenido; es decir, contemplar los procesos individuales del estudiantado y los procesos sociales del centro educativo, comunidad y país que se encuentran vinculados con la construcción del significado de cada contenido.

6. La enseñanza como acto cultural (Torres, 1998) vincula este proceso con elementos del papel cultural, la estructura económica y social y subjetividades. Incorporar esta premisa permite construir y deconstruir el currículo más allá del reduccionismo didáctico y la vivencia del aula. 
7. El aprendizaje es un hecho cultural construido dentro de sistemas culturales semióticos que permiten el desarrollo de funciones psíquicas superiores del estudiantado en el marco de su desarrollo cultural (Vigotsky, 2001). El diseño curricular costarricense requiere estructurar la propuesta educativa en línea con esta premisa, lo cual exige un rediseño de los ciclos educativos, las formas de medición del rendimiento académico, transformación de las actividades de mediación y la vivencia del aula, transformación de los materiales y un proceso de transformación de los roles de educadores y educadoras.

8. La evaluación es un proceso de diálogo (Santos, 1995), comprometida con un proceso democrático (Santos, 1999, 2003 y 2010), lo que equivale a una ruptura determinante con la visión reduccionista centrada en la medición seudoobjetiva. A partir de esta visión, el currículo debe establecer la flexibilidad necesaria para la contextualización curricular y el cambio de la normativa vigente para permitir e impulsar la creación de las evaluaciones integrales, alternativas y relevantes.

9. El educador y la educadora se conciben como intelectuales transformadores (Giroux, 1990; Giruox y McLaren, 1998) capaces de comprender y transformar las realidades visibles e invisibles que determinan, o al menos pretenden determinar, los procesos de aprendizaje y la contextualización curricular. En este aspecto, el currículo costarricense requiere realizar procesos de diálogo con las instituciones formadoras del personal formador para asegurar coherencias entre el diseño crítico y las características de docentes que aportan al país.

La definición de los fundamentos para un currículo crítico permite la apertura de nuevos escenarios para la investigación educativa, entre ellos: la construcción de un perfil de ser humano y nuevos perfiles de ingreso-salida a cada ciclo educativo, transformación de los procesos de selección y organización de contenidos así como de las actividades de mediación y evaluación, reorganización pedagógica-administrativa para la democratización del centro educativo y la incorporación de disciplinas de las ciencias sociales para el análisis del fenómeno educativo. 


\section{Referencias}

Althusser, L. (1989). La filosofia como arma de la revolución. México D.F: Siglo XXI.

Apple, M. (1996a). El conocimiento oficial. España: Paidós.

Apple, M. (1996b). Política cultural y educación. Madrid: Morata.

Apple, M. (1997a). Educación y poder. España: Paidós.

Apple, M. (1997b). Teoría crítica y educación. España: Niño y Dávila Editores.

Barba, M., Cuenca, M., y Rosa, A. (2007). Piaget y L. S. Vigotsky en el análisis de la relación entre educación y desarrollo. Revista Iberoamericana de Educación, 42(7), 1-12.

Bourdieu, P. (1997). Capital cultural, escuela y espacio social. México: Siglo Veintiuno.

Bourdieu, P. y Passeron, J. (2001). La reproducción: Elementos para una teoría del sistema de enseñanza. España: Popular.

Cabello, M. J. (2003). Imaginar e instituir la educación globalizada. En J. Martínez (Coord.), Ciudadanía, poder y educación. Madrid: GRAO.

Chaves, A. (2001). Implicaciones educativas de la teoría sociocultural de Vigotsky. Revista Educación, 25(2), 59-65.

Domínguez, J. y Lugo, A. (2013). La ciencia social crítica y la escuela de Fráncfort. Revista Visión Electrónica, 7(2), 205 - 213.

Durkheim, É. (1975). Educación y sociología. España: Península.

Fernández, F. (Coord.). (2003). Sociología de la educación. Madrid: Pearson Educación.

Fernández, F. (2003). El estudio sociológico de la educación. En F. Fernández (Coord.), Sociología de la educación. Madrid: Pearson Educación.

Fernández, I. (2011). Intervención pedagógica desde un marco ético-crítico. Revista Iberoamericana de Educación, 57(1), 1-8. Recuperado de http://www.rieoei.org/deloslectores/4443FdezMoujan.pdf

Freire, P. (1977). La educación como práctica de la libertad. México: Siglo Veintiuno.

Freire, P. (2005). Pedagogía del oprimido. México, D.F: Siglo XXI.

Freire, P. (1990). La naturaleza política de la educación: Cultura, poder y liberación. España: Paidós. 
Gimeno, J. (1998). Poderes inestables en educación. Madrid: Morata.

Giroux, H. (2006). La escuela y la lucha por la ciudadanía: Pedagogía crítica de la época moderna. México, D.F: Siglo XXI.

Giroux, H. (2003). Teoría y resistencia en educación. México, D.F: Siglo XXI.

Giroux, H. (1997). Cruzando los límites: Trabajadores culturales y políticas educativas. Barcelona: Paidós.

Giroux, H. (1990). Los profesores como intelectuales. Barcelona: Paidós.

Giroux, H y McLaren, P. (1998). Lenguaje, escolarización y subjetividad: Más allá de una pedagogía de reproducción y resistencia. En H. Giroux y P. McLaren (1998), Sociedad, cultura y educación. Madrid: Niño y Dávila Editores.

Granados, A. (2003). Las funciones sociales de la escuela. En F. Fernández (Coord.), Sociología de la educación. Madrid: Pearson Educación.

Magendzo, A. (2003). Pedagogía crítica y educación en derechos humanos. Revista de Pedagogía Crítica, 2(2), 19-27 Recuperado de http://bibliotecadigital.academia.cl/bitstream/handle/123456789/1624/019-027.pdf?sequence=1\&isAllowed=y

Masjuan, J. (2003). ¿Qué es sociología? Algunos conceptos básicos. En F. Fernández (Coord.). Sociología de la educación. Madrid: Pearson Educación.

McLaren, P. (1998). Los símbolos en el aula y las dimensiones rituales de la escolaridad. En H. Giroux y P. McLaren (1998), Sociedad, cultura y educación. España: Niño y Dávila Editores.

McLaren, P. (2003). Pedagogía crítica en la época de la resignación. Revista de Reflexión Socioeducativa, 2, 8- 12.

McLaren, P. (1997). Pedagogía crítica y cultura depredadora. España: Paidós.

McLaren, P. (1996). Pedagogía crítica, resistencia cultural y la producción del deseo. Argentina: Aique Editores.

Miranda, G. (2007). Política curricular, crisis de legitimación y hegemonía neoliberal. Una visión desde la sociología de la educación critica. Revista de Ciencias Sociales, 115, 13-34.

Miranda, G. (2001). Capitalismo global y cambio educativo. Los fundamentos estructurales e ideológicos de la política educativa neoliberal. Revista Educare, 4(7), 13-42. 
Molina, I. (2007). Educación y sociedad en Costa Rica: De 1821 al presente (una historia no autorizada). Diálogos Revista Electrónica de Historia, 8(2), 149-356. Recuperado de http://historia.fcs.ucr. ac.cr/articulos/2007/vol2/7vol8n2imolina.pdf

Pineda, W. (2011). La teoría de la mente en la educación desde el enfoque socio-histórico de Lev Vigotsky. Educación y Humanismo, 13(20), 220-233.

Radford, L. (2004). Semiótica cultural y cognición. Conferencia plenaria en la XVIII Reunión Latinoamericana de Matemática Educativa. Universidad Autónoma de Chiapas. Chiapas.

Robertson, S. (1994). "New Production Concepts" and the Reconstruction of Teacher Education: a Post-Fordist Crtique. Australian Journal of Teacher Education, 19 (2), 50-59. Recuperado de http:// ro.ecu.edu.au/cgi/viewcontent.cgi?article $=1249 \&$ context $=$ ajte

Santos, M. (2010). El proyecto de centro: Una tarea comunitaria, un proyecto de viaje compartido. En J. Gimeno (Comp), Saberes e incertidumbres sobre el curriculum. Madrid: Morata.

Santos, M. (2003). Arte y parte: Desarrollar la democracia en las escuelas. España: Homo Sapiens.

Santos, M. (1999). Democracia escolar o el problema de la nieve frita. En P. Manzano (Coord.), Volver a pensar la educación (Vol. I). Madrid: Morata.

Santos, M. (1995). La evaluación: Un proceso de diálogo comprensión y mejora. Madrid: Aljibe.

Soares, C. (2012). A educação a partir das barbas de marx. Praxis Filosófica, 34, 671-1765.

Torres, J. (2007). Educación en tiempos del neoliberalismo. España: Morata.

Torres, J. (1998). El currículum oculto. Sexta Edición. España: Morata

Toruño, C. (2015). Reformas curriculares 2006-2014: Del ajuste pedagógico neoliberal a la reinstauración del modelo pedagógico socialdemocrata. Revista Rupturas, 52(2), 21-48. Recuperado de http:/investiga.uned.ac.cr/revistas/index.php/rupturas/article/ view/881/789

Toruño, C. (2011). La configuración de la ciudadanía en los programas de estudio de la Educación Cívica al iniciar el siglo XXI: El caso del elemento político de la ciudadanía. Actualidades 
Investigativas en Educación, 11(2), 1-30. Recuperado de http:// revista.inie.ucr.ac.cr/index.php/aie/article/download/453/452

Toruño, C. (2010). Los fundamentos curriculares de la ciudadanía en un Estado neoliberal: El caso del sistema educativo costarricense. Actualidades Investigativas en Educación, 10(2), 1-25. Recuperado de http://revista.inie.ucr.ac.cr/index.php/aie/article/ download/408/407

Tyler, W. (1996). Organización escolar. Madrid: Morata.

Vargas, L. (2002). Costa Rica, 1985-1997: Liberalización y ajuste estructural o la autodestrucción del neoliberalismo. Costa Rica: EUNED.

Villarreal, R. (1986). La contrarrevolución monetarista: Teoría, política económica e ideología del neoliberalismo. México: Fondo de Cultura Económica.

Vigotsky, L. (2001). Obras escogidas (Tomos I, II, III y IV). Madrid: Machado Libros. 